describing the application of new techniques to Zeeman spectroscopy, P. M. Griffin and K. L. Vander Sluis (Oak Ridge) showed how a combination of electrodeless discharge sources, very uniform magnetic fields of about 33,000 oersteds and an echelle spectrograph can produce very well-resolved Zeeman patterns; results off the plates were obtained with the aid of a high-speed electronic computer (Oracle).

H. H. Nielsen and K. N. Rao (Ohio State University) discussed measurements connected with the theory of centrifugal stretching constants in linear polyatomic molecules. The results from an snalysis of the absorption spectrum of thallous chlorids taken with a Fabry-Perot interferometer crossed with a 21-ft. grating instrument were given by $R$. R. Kadesch, J. C. Moldenhauer and J. G. Winans (Wisconsin), and G. W. Charles (Oak Ridge) discussed the vibrational analysis of the spectrum of $\mathrm{Po}_{2}$. The use of absorption and fluorescence spectra to derive the symmetry of the micro fields about europium ions in methanol $\left(C_{2 v}\right)$ and in water $\left(D_{2 h}\right)$ was described by S. Freed, E. V. Sayre and D. G. Miller (Brookhaven). Further results from the polarization, absorption and fluorescent spectra of single crystals at temperatures between $4^{\circ}$ and $300^{\circ} \mathrm{K}$. of some praseodymium and europium salts obtained by Freod and Sayre give much information on the micro-crystalline fields surrounding the ions.

After a discussion of the derivation of selection rules for rare-earth ion spectra in crystals, R. A. Satten (University of California) showed how these are violated in the spectra of neodymium bromate and ethyl sulphate. The breakdown in the solection rules is partially attributed to interaction of electronic and vibrational motion. 'The possible electronic configuration of the $\mathrm{Am}^{+3}$ ion was briefly discussed by J. G. Conway, R. D. McLaughlin, B. B. Cunningham (Berkeley) and D. M. Gruen (Argonne) following a description of the experimental absorption (over the range 3000-12,000 A.) and fluorescent (range 30008800 A.) spectra of single crystals of lanthanum chloride containing 0.04 and 0.2 mole per cent amoricium chloride. The Raman spectrum of uranium hexafluoride and the infra-red spectra of neptunium hexafluoride and plutonium hexafluorido have been observed by J. K. Brody, H. H. Claassen and B. Weinstock (Argonne), and all six fundamental frequencies arising from the $\mathrm{O}_{h}$ symmetry determined. The absorption spectra of the last two fluorides have also been studied between 5000 and $25,000 \mathrm{~A}$., and an interpretation of the fine structure seen in some of the bands was discussed.

K. W. Meissner and E. C. Finckh (Purdue University) discussed the possible use of a calcium atomicbeam lamp for high-precision measurements of wave-length. A half-width of $9 \times 10^{-3} \mathrm{~cm} .^{-1}$ was observed in preliminary experiments. A complete and consistent sot of oscillator strengths for dipole transitions from the ground-level of the helium atom were given by W. F. Millor and R. L. Platzman (Purdue). From a study of the unusual Doppler effects in calutron ion sources, J. R. McNally, jun., and M. R. Skidmore (Oak Ridge) showed that these should be attributed to an ordered ionic drift about the arc column with ion velocities often exceeding $10^{6} \mathrm{~cm} . / \mathrm{sec}$.

The use of nuclear magnetic resonance to determine isotope ratios $\left({ }^{1} \mathrm{H} /{ }^{2} \mathrm{H}\right.$ and $\left.{ }^{6} \mathrm{Li} /{ }^{2} \mathrm{Li}\right)$ wos summarized by B. E. Holder and M. P. Klein (California). The techniques described included both a relative and an absolute method. The natural $2 \mathrm{Li} /{ }^{6} \mathrm{Li}$ ratio was found to be 11.8. The same authors also discussed measurement of nuclear magnetogyric ratios by nuclear magnetic resonance. Where direct observation is not possible because of such causes as residual atomic paramagnetism, nuclear quadrupole interaction, low abundances or small magnetogyric ratios, a double resonance technique can be tried. In this method the atom under investigation is bonded to an atom with more favourable properties. Under suitable conditions, by an indirect spin-spin interaction, the constants of the unknown atom can often be determined. L. S. Goodman (Argonne), in a paper on atomic beam measurements of radioactive isotopes, discussed problems connected with the source, magnetic field, calibration and detection.

Much of the work discussed was in the course of publication or had been published, and therefore no arrangements were made for issuing any detailed account of the symposium.

L. F. H. BoveY

\section{PHYSIOLOGY OF FUNGAL PARASITISM}

CTUDIES of the physiology of fungal parasitism, $\checkmark$ begun by Prof. W. Brown many years ago at the Imperial College of Science and Tochnology, are being maintained and extended, special attention boing given to the part played by the enzymes which bring about the dissolution of the cellular structure and the death of tissues. In the Annals of Botany $(20,77 ; 1956)$ three investigations are reported. J. S. Cole gives an account of the pathogenicity of Botrytis cinerea, Sclerotinia fructigena and $S$. laxa, with special reference to the action of their pectolytic enzymes. He has found that although these three fungi cause rotting of apple tissue and the death of the protoplasts, very little pectolytic activity can be detected in the rotting tissue.

Pectolytic activity was measured by methods involving (a) maceration of plant tissues, (b) viscosity and reducing group determinations in pectic substrates, (c) increase in acidity of pectin. By these methods it was shown that pectolytic enzymes were produced by all three fungi in synthetic media. With $S$. fructigena, which was the only fungus studied in detail, replacement of glucose by pectin increased the formation of pectolytic enzymes. When various apple extracts were used as culture media, little or no pectolytic activity was detectable. With all three fungi the presence of apple juice in a culture medium, which by itself was suitable for enzyme formation, resulted in the suppression of pectolytic activity. Oxidized apple juice had a pronounced effect in deactivating certain pectolytic enzymes, an effoct which was especially marked with $B$. cinerea. This points to an interaction between the pectolytic and oxidizing systems and introduces a new line of approach to the study of the biochemical interaction between host and parasite.

R. K. Singh and R. K. S. Wood, in an investigation of the production and properties of the pectic enzymes secreted by Fusarium moniliforme, have observed that this fungus secreted macerating enzymes in liquid media only when these contained certain natural extracts, pectic substances, or galacturonic acid. Apple extract was unsuitable for enzyme secre. tion and also inhibited enzyme secretion in synthetic 
media otherwise suitable. Protopectinase activity of solutions was highest in the $p \mathrm{H}$ range $8 \cdot 0-9 \cdot 0$, was rapidly lost at temperatures above $50-60^{\circ} \mathrm{C}$., and was reduced by concentrations of phosphate higher than $0.02 M$. The enzyme was partially purified by precipitation in 60 per cent acetone at $p H \quad 6 \cdot 0$. Protopectinaso solutions also contained an enzyme which reduced the viscosity of solutions of various pectic substances. The properties of this enzyme were, in general, similar to those of protopectinase. When activity of enzyme solutions was measured by the liberation of reducing groups, pectate solutions were more rapidly degraded than wore solutions of a high methoxyl pectin, particularly in the early stages of the reaction. Partition chromatography of the products formed showed that pectate and pectin were degraded in different ways. Although the pathogen roadily secreted protopectinase in potato extract, potato tubors were not readily parasitized. In contrast, Fusarium avenaceum, which readily attacked tubers, secreted little protopectinase in potato extract.

S. C. Gupta has examined the production of pectolytic enzymes by Pythium de baryanum. Among other things, he observed that the incorporation of sodium chloride in a synthetic medium stimulated the pecto. lytic activity of cultures of Pythium de baryanum. The chloride ion appeared to be mainly responsible for this effect ; on the other hand, presence of the calcium ion depressed enzymic activity. Glucose, fructose and mannose were about equally suitable for growth and enzyme production. Sucrose, if used as sole carbohydrate source, gave good mycelial growth but poor: enzyme production; but if a small proportion wass replaced by glucose, enzyme production was as good as on glucose itself. Galactose gave very poor growth and negligiblo enzymo production. For optimum production of pectolytic enzyme, glucose (or fructose or mannose) requires to be autoclaved in a somewhat alkaline medium - very conveniently with the dipotassium hydrogen phosphate or potassium phosphate of the nutrient medium. A yellow to brown coloration (duo to caramolization) is produced in the process ; but the stimulating factor is not bound up with the colouring substance. 'The same stimulating effect on enzyme production was obtained by adding to the nutrient medium a small quantity of glucose which had been dry-heated at $150^{\circ} \mathrm{C}$. for $20 \mathrm{~min}$. Partition chromatographic analysis suggested that the stimula. ting substance was probably glyceraldehyde, though it is not excluded that other breakdown products of sugars may also play a part.

\section{CARNEGIE TRUST FOR THE UNIVERSITIES OF SCOTLAND \\ REPORT FOR 1954-55}

$\mathrm{T}$ HE fifty-fourth annual report of the Executive Committeo of the Carnegie Trust for the Universities of Scotland, covering the academic year 1954-55*, records an increase in the numbers of studonts from 1,408 to 1,502 , chiefly in science and medicine, to whom assistance was given with their class fees, the amount expended increasing

* Carnegie Trust for the Universities of Scotland. Fifty-Fourth Annual Report (for the Yoar 1954-55) submitted by the Executive (Edinburgh: Carnegie Trust for the Universities of Scotland, 1956.) from $£ 22,007$ to $£ 24,232$. Problems created for the Trust by the bursary awards made by local education authorities in terms of the Education (Scotland) Act are by no means solved, and the Executive Committeo directs attention to the, apparently, growing assumption of many students that the Carnegie Trust grant is to be applied for as an addition to the education authority bursary whatever be the value of that bursary. Strongly emphasizing its declared intention to limit its assistance in this direction to holders of local education authority bursaries whose circumstances, taken as a whole, appear genuinely to warrant additional help, the Executive Committee expresses its desire for a proper appreciation of this policy and the reasons for it on the part of directors of education, university advisers of studies and similar officials.

Expenditure on the Trust's research scheme totalled $£ 33,155$, and its various features were maintained. Three senior scholarships and fifty-three scholarships wore awarded or renewed, some being supplements to scholarships and bursaries gained from other sources, and twenty-three of these were used for postgraduate study outside the parent university. The high value of this part of the programme is stressed in the report, as is that of the scheme, inauguratod in 1950 , which affords annually ten members of university staffs, moro than thirty years of age, the opportunity of study abroad. Eleven such awards were made in $1954-55$, three being in scientific subjects, two in medicino and one in African studies. Besides the annual grant made to the Royal Society of Edinburgh and to the Scottish Historical Revie?v, eleven learned societies in Scotland wore assisted in the publication of their transactions and journals ; in addition to an immediate grant of $£ 2,000$ to the Scottish National Dictionary, the Scottish Dictionaries Joint Council was invited to sub. mit plans by which $£ 20,000$ could be used for ensuring substantial developments within a reasonably short period, and this sum has been placed at the Couneil's disposal. Repaymonts by former beneficiaries declined slightly from $£ 1,921$ from thirty-six former beneficiaries to $£ 1,868$ from thirty-three beneficiaries.

Besides particulars of grants made under the ninth quinquennial distribution, October 1, 1952-September 30,1957 , there are appended the terms of the scheme for the endowment of postgraduate study and research and a summary of reports received from the advisers to the Trust on the work of investigators under the research scheme during 1954-55. In the mathematical, physical and engineering section, the fellowships of $R$. Giles on quantum field theory at the Institute of Theoretical Physics, Copenhagen, and of D. Chisholm on the flow of two-phase mixtures at the University of California are stressed as outstanding. K. M. Swanson's work on nuclear magnetic resonance was again successful, and in connexion with J. V. Thomson's work in fluid dynamics it is suggested that the Scottish universities should co-operate to provide an electronic computer with the strong support of the Carnegie Trust.

In the chemistry section, J.S. S. Reay, working on organic ammonium derivatives of montmorillonite, has noted interesting relations between the molecular volume of the ammonium ions and the adsorptive capacity for hydrocarbons. J. M. Beaton's work at the Royal Technical College, Glasgow, has been instrumental in establishing the constitution of taraxerol; also, by establishing the orientation of the carboxyl group in glycyrrhetic acid, he has com. 